\title{
Striking a balance: Surveillance of non-small cell lung cancer after resection
}

\author{
Brendan T. Heiden, MD, Melanie P. Subramanian, MD, MPHS, Varun Puri, MD, MSCI, and \\ Benjamin D. Kozower, MD, MPH
}

Feature Editor's Note-Resection for stage I non-small cell lung cancer results in long-term disease-free and overall survival in a majority fraction of patients; however, "cure" is a term that oncology providers use sparingly. Recurrence and new primary lung cancers are still too common in this cohort and are even more frequent in individuals with resected stage II and III non-small cell lung cancers. Consequently, radiographic surveillance with chest tomography imaging has become routine in the ongoing care of the patient with surgically resected lung cancer. Presented herein is the state-of-the-art in this young field in a format that is expected to benefit all readers. In many practices, thoracic surgeons manage the longitudinal care of their patients, and this Feature Expert Opinion will be particularly valuable for this audience. The academic will be called to examine the value of surveillance chest tomography in a population whose primary mode of recurrence is distant. The practical will find support of surveillance as a "screening" methodology for new lung cancers in a group that is, by definition, high risk. Most all will be surprised by the level of available evidence that informs the frequency and duration of surveillance imaging after lung cancer resection and will better understand the reasons for the variable patterns of surveillance that are observed today. For those of us who have suspected an overuse of surveillance imaging, perhaps in exchange for a perceived benefit of early disease detection, this article will prove a valuable reference in support of a nonoverzealous surveillance regimen.

\section{Bryan M. Burt, MD}

Imaging surveillance after non-small cell lung cancer (NSCLC) resection has been a routine part of cancer care. Surveillance occurs in asymptomatic patients with the purposes of detecting recurrent disease; identifying new

From the Division of Cardiothoracic Surgery, Washington University School of Medicine, St Louis, Mo.

Funded in part by National Institutes of Health 5T32HL007776-25 (to B.T.H.) and Veterans Administration 1I01HX002475-01A2 grant (to V.P.).

Received for publication Aug 28, 2020; revisions received Sept 29, 2020; accepted for publication Oct 8, 2020; available ahead of print Dec 10, 2020.

Address for reprints: Benjamin D. Kozower, MD, MPH, 660 S Euclid Ave, Campus Box 8234, St Louis, MO 63110 (E-mail: kozower@wustl.edu).

J Thorac Cardiovasc Surg 2021;162:680-4 $0022-5223 / \$ 36.00$

Copyright (c) 2021 Published by Elsevier Inc. on behalf of The American Association for Thoracic Surgery

https://doi.org/10.1016/j.jtcvs.2020.10.166

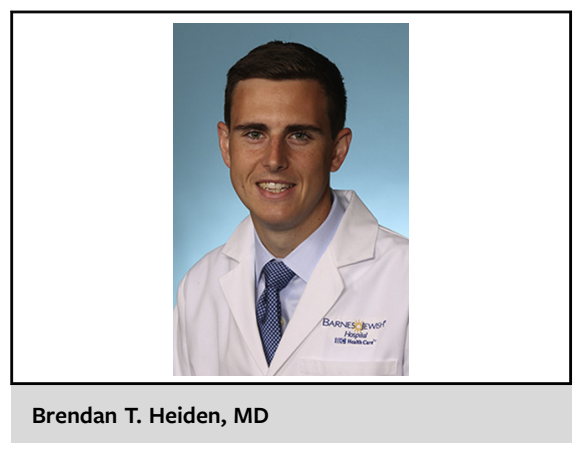

CENTRAL MESSAGE

Imaging surveillance following lung cancer resection remains controversial due to a lack of prospective studies. Recent literature suggests that patients do not benefit from more frequent imaging.

See Commentaries on pages 685 and 686 .

primary lung cancers; monitoring for treatment side effects; and managing patient anxiety about recurrence. ${ }^{1}$ After all, even with complete resection, recurrence occurs in $30 \%$ to $70 \%$ of patients at 5 years. ${ }^{2,3}$ Early detection among these patients can lead to more aggressive treatment and potentially improved survival. ${ }^{4}$ The urge to screen too frequently, however, must be balanced with potential untoward consequences, particularly false-positive findings, which are common. ${ }^{5}$ Unfortunately, recommendations regarding surveillance imaging-both the frequency and modality-vary widely in clinical practice and are based largely on expert opinion due to limited high-quality evidence.

While most expert guidelines currently recommend relatively frequent surveillance imaging in the postoperative period (at 3- to 6-month intervals), recent evidence suggests that such imaging routines have little to no effect on patient survival. ${ }^{3,6-9}$ One potential explanation for this is that early detection of recurrent or metastatic disease, with the largely ineffective salvage therapies currently available, has little clinical impact. ${ }^{10}$ Hopefully as new therapies (targeted therapies, immunotherapies, etc) continue to 
improve, recurrences can be treated with more meaningful outcomes. ${ }^{11}$ However, given our current arsenal, clinicians likely err toward surveilling postoperative patients too aggressively with little to offer these patients if and when recurrent disease is discovered.

\section{IMAGING MODALITY}

Computed tomography (CT) of the chest is superior to chest radiograph (CXR) for detecting lung cancer recurrence. $^{3,6,8}$ The National Lung Screening Trial (NLST), although not explicitly applicable to postresection surveillance, likely provides the best evidence for this. The trial found that screening chest CT was associated with greater detection rates and lower mortality compared with CXR. ${ }^{12}$ In the postoperative period, similar observations exist. Hanna and colleagues ${ }^{13}$ prospectively studied 271 patients following lung cancer resection with CXR and minimal-dose CT scan. They found that CT was more sensitive and had a greater negative predictive value for detecting recurrent or new disease. As such, multiple professional guidelines recommend surveillance CT. ${ }^{3,6,8}$ Interestingly, it is unclear whether these guidelines are followed broadly in clinical practice. A recent study by McMurry and colleagues ${ }^{1}$ found that only $46.8 \%$ of patients in the National Cancer Database $(\mathrm{n}=9668)$ with stage I-III lung cancer were surveilled with CT imaging following resection. Similarly, Erb and colleagues ${ }^{14}$ found that only $61.4 \%$ of patients with stage I NSCLC in the Surveillance, Epidemiology and End Results-Medicare linked database ( $\mathrm{n}=9321)$ underwent "appropriate" surveillance (by CXR or CT at specific intervals) following resection. Of note, both of these studies included relatively old cohorts during a period when guidelines varied more widely. Evidence on the use of CT in modern practice remains sparse.

It is worth noting, however, that the superiority of CT over CXR for detecting disease recurrence may not translate to a survival advantage. IFCT-0302 is an ongoing phase III clinical trial in Europe evaluating surveillance CT versus CXR for completely resected NSCLC. ${ }^{15}$ Patients were randomized to CXR or thoracoabdominal CT scan every 6 months for 2 years, followed by annual imaging. A total of 1775 patients were randomized in the study. At 8 years of follow-up, no difference in overall survival has been observed. This study suggests that aggressive and early detection of recurrent disease does not improve survival, which is likely a result of ineffective salvage therapies. In other words, patients with recurrence have poor outcomes regardless of how early the recurrence is discovered because we have relatively little to offer these patients therapeutically. A study by Wong and colleagues ${ }^{4}$ demonstrated this finding by comparing survival between patients with asymptomatic (ie, recurrence found on routine surveillance) and symptomatic (ie, recurrence found outside of routine surveillance) lung cancer recurrence. Their study showed that even though asymptomatic patients were more likely to receive salvage therapy, overall survival outcomes were universally poor between the 2 groups and likely confounded by lead-time bias. As the IFCT-0302 study is still ongoing, its results will need to be closely examined upon completion.

The use of contrast enhancement is also debated. For example, the American Society of Clinical Oncology (ASCO) guidelines "prefer" contrasted chest $\mathrm{CT}^{6}$; meanwhile, the National Comprehensive Cancer Network recommends CT of the chest either with or without contrast. ${ }^{8}$ Contrast enhancement is particularly useful for examining enlarged hilar nodes; it is less critical for examining lesions in the lung parenchyma. Since local recurrence tends to be greater within the first 2 years after surgery, ${ }^{16,17}$ contrasted studies are generally preferred during the first 2 years of follow-up for evaluation of hilar recurrence ( $10 \%-20 \%$ of recurrences). ${ }^{2,4}$ Beyond this time, noncontrasted low-dose CT (LDCT) may be adequate, with a larger emphasis on detecting new primary cancers within the lung parenchyma. Obviously, additional studies addressing contrast utility are important, especially given its potential adverse effects and need for insertion of a peripheral intravenous line.

Few recommendations exist regarding the utility of routine abdominal imaging. The ASCO 2020 guidelines recommend selective abdominal imaging with chest $\mathrm{CT}$ including the adrenal glands; however, ASCO does not give additional recommendations for further abdominal or pelvis imaging. ${ }^{6}$ Two prevailing theories against routine cross-sectional abdominal imaging are (1) abdominal recurrences are relatively rare when compared with other sites (like the lung) ${ }^{18}$ and (2) abdominal recurrences portend stage IV disease, where early detection may have little survival benefit. The results of IFCT-0302 may shed additional light on the utility of abdominal imaging since these patients underwent routine thoracoabdominal imaging.

Brain imaging in asymptomatic patients following resection is generally not recommended. ${ }^{3,6,8}$ Although recurrence rates to the brain range from $5 \%$ to $40 \%$, no randomized trials have examined routine brain imaging postoperatively. ${ }^{6}$

Positron emission tomography (PET) has also been examined in postoperative surveillance. Gambazzi and colleagues ${ }^{19}$ prospectively randomized 96 patients following curative-intent therapy to PET-CT or chest CT every 6 months for 2 years. PET was not superior to CT for detecting recurrence with similar sensitivity and specificity between the 2 modalities. Reddy and colleagues ${ }^{20}$ similarly observed no difference in time to recurrence or overall survival among patients with stage III cancer followed by PET versus CT. Another study by Choi and colleagues ${ }^{21}$ examined 358 patients following resection who received both PET and CT imaging concurrently. PET identified recurrences that were not recognized on CT. However, the 
authors noted that ground-glass lesions and small adenocarcinomas were often missed on PET, calling into question the utility of this modality for recognizing early recurrence and new primary lung malignancies. Without clear evidence supporting PET as a routine surveillance modality, and given its high cost and radiation exposure, several groups recommend against PET or other functional imaging for lung cancer surveillance. ${ }^{3,6,8}$

\section{IMAGING FREQUENCY}

To understand when and how often imaging should be performed, it is helpful to consider how the purpose of surveillance imaging may vary over the postoperative course. Recurrence is most common during the first 2 years following treatment. ${ }^{16,17}$ In theory, this may justify more frequent and wider (ie, abdominal) imaging during the immediate postoperative course, especially since a majority of disease recurs at distant sites. ${ }^{2}$ Beyond this point, imaging largely identifies new primary lung cancers, with a risk as high as $2 \%$ to $7 \%$ per patient per year. ${ }^{17,22}$ Hence, it is generally recommended that surveillance can be relaxed at 2 years to that of a "high-risk" patient, similar to the NLST, with annual screening-interval chest CTs. Obviously, overlap exists between these groups (ie, recurrences occur beyond 2 years; new secondary malignancies occur before 2 years), but this logic provides some context to the intervals at which a patient may be surveilled.

Unfortunately, current guidelines are heterogeneous, as there are few strong studies examining optimal surveillance frequency. Table 1 highlights current surveillance recommendations from several professional organizations. ${ }^{3,6-9}$ All groups acknowledge that their recommendations are based on low-quality evidence. However, in general these guidelines recommend aggressive initial surveillance using CT imaging every 3 to 6 months followed by a more relaxed imaging schedule.

Several studies call into question such surveillance strategies, however. McMurry and colleagues performed a Commission on Cancer special study of existing NCDB data augmented with granular clinical data out to 5 years following surgical resection. ${ }^{1}$ They examined 4463 patients with stage I-III NSCLC who underwent chest CT. Patients were placed into surveillance groups based on the interval at which they received their first postoperative scan: 3,6 , or 12 months. This study found that more frequent surveillance was not associated with improved, risk-adjusted overall survival. Similarly, more frequent surveillance was not associated with improved postrecurrence survival. A second and related study by Subramanian and colleagues ${ }^{23}$ focused on a patient population with stage I lung cancer. A total of 2442 patients were followed for 5 years. Similarly, overall survival did not vary between high-, medium-, and lowintensity surveillance groups. Together, these studies call into question guidelines recommending screening CTs at 3- to 6-month intervals, as such practices may be too aggressive with little impact on patient outcomes. Current data seem to suggest that surveillance imaging should occur at least annually but no more frequently than biannually. Strong recommendations beyond this are hard to make at this time, given a lack of prospectively collected data. ${ }^{1,10,23}$

Appropriate long-term surveillance, especially beyond several years after surgery, is similarly challenging. Han and colleagues ${ }^{24}$ found in a review of more than 20,000 lung cancer survivors who had survived beyond 5 years, the 10-year risk of a second primary lung cancer was $8.4 \%$. Notably, this risk is twice that of the NLST

TABLE 1. Current guidelines for lung cancer surveillance following resection

\begin{tabular}{|c|c|c|}
\hline Organization & Recommendations & Miscellaneous \\
\hline $\mathrm{NCCN}$ & $\begin{array}{l}\text { Stage I-II: H\&P, chest CT } \pm \text { contrast every } 6 \text { mo for } 2-3 y \text {, then } \\
\text { annual LDCT (duration unspecified) } \\
\text { Stage III-IV: H\&P, chest CT } \pm \text { contrast every } 3-6 \text { mo for } 3 y \text {; then } \\
\text { annual LDCT (duration unspecified) }\end{array}$ & $\begin{array}{l}\text { PET/CT and brain MRI not recommended } \\
\text { Continue smoking-cessation counseling }\end{array}$ \\
\hline ASCO & $\begin{array}{l}\text { Chest CT with contrast (including adrenal glands) every } 6 \text { mo for } 2 \mathrm{y} \text {; } \\
\text { then annual LDCT (duration unspecified) }\end{array}$ & $\begin{array}{l}\text { Unclear benefit of additional abdominal/pelvis imaging } \\
\text { PET/CT and brain MRI not recommended } \\
\text { Biomarker testing not recommended }\end{array}$ \\
\hline $\mathrm{ACCP}$ & $\begin{array}{l}\text { Chest CT every } 6 \text { mo for } 2 \mathrm{y} \text {; then annual chest CT (duration } \\
\text { unspecified) }\end{array}$ & $\begin{array}{l}\text { Surgeon involvement in surveillance recommended } \\
\text { PET or other functional imaging not recommended } \\
\text { Biomarker testing not recommended }\end{array}$ \\
\hline ESMO & $\begin{array}{l}\text { H\&P, chest CT with contrast "at least at } 12 \text { and } 24 \text { mo" but possibly } \\
\text { as often as every } 6 \text { mo for } 2-3 \text { y (individualized); then annual H\&P } \\
\text { and chest CT (duration unspecified) }\end{array}$ & $\begin{array}{l}\text { Surveillance should be individualized } \\
\text { Continue smoking-cessation counseling }\end{array}$ \\
\hline AATS & Chest CT every 6 mo for $4 \mathrm{y}$; then annual LDCT & $\begin{array}{l}\text { Continue annual screening until } 79 \mathrm{y} \text { of age or unable to } \\
\text { undergo treatment due to functional limitations }\end{array}$ \\
\hline
\end{tabular}

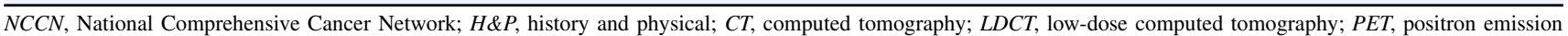
tomography; MRI, magnetic resonance imaging; ASCO, American Society of Clinical Oncology; ACCP, American College of Chest Physicians; ESMO, European Society of Medical Oncology; AATS, American Association for Thoracic Surgery. 
$(3.7 \%)$, suggesting that lung cancer survivors should undergo at least annual LDCT to detect second primary lung cancers. ${ }^{25}$

\section{GAPS IN KNOWLEDGE}

Unfortunately, the literature examining postresection surveillance imaging does not meet the current bar for evidence-based medicine. One reason for this is that these studies are inherently difficult to perform. Most of the national databases that include surgically treated lung cancer patients do not routinely collect imaging studies that were performed during follow up. Indeed, the studies of McMurry and colleagues ${ }^{1}$ and Subramanian and colleagues $^{23}$ are unique for examining tumor registry (not administrative) data in which supplementary longitudinal patient chart extraction was later performed. Such studies are obviously expensive with limited funding. In addition, observational and retrospective imaging surveillance studies are severely limited by lead-time and length-time bias, which can challenge the validity of findings in this particular area of research. Prospective studies-like IFCT-0302 - are critically needed to help address the current knowledge gaps and to establish best-practices. Several attempts have been made to obtain funding from the Patient-Centered Outcomes Research Institute and the National Cancer Institute but have not been funded as the cost of these studies requiring long term follow-up exceeded their priority in the eyes of the funding agencies.

Another challenge with this field is that therapies are constantly evolving. The studies by Subramanian, McMurry, Wong, and IFCT-0302 would seem to suggest that expedient commencement of salvage therapy has little impact on patient survival regardless of how quickly recurrent disease is detected. In other words, treatment options are limited and ineffective when recurrent disease is identified. These conclusions, however, are in the context of whatever salvage therapies existed when these studies were performed. Rapidly improving targeted therapies, immunotherapies, and radiation therapy are now common place. $^{11}$ Therefore, early recurrence detection may soon confer a survival advantage in the context of new salvage therapies. Similarly, early detection of second primary lung cancers seems obviously beneficial. This will need to be carefully considered as surveillance and treatment guidelines continue to evolve.

The modality and frequency of imaging are but the tip of the iceberg, given the true clinical complexity of cancer surveillance. Surgical patients present at a variety of clinical and pathologic stages. It is well-established that recurrence rates vary widely between an early stage I cancer and a locally advanced stage III cancer. However, a majority of the guidelines do not give stage-specific recommendations. Guidelines for stage-specific surgical follow up are needed, but the data for them do not exist. Several additional disease- and patient-related factors could also influence surveillance regimens (ie, inadequate lymph node sampling during the operation, sub-lobar resection, close margins, smoking status, etc). This complexity highlights that the optimal surveillance strategy should include some patient specific factors including patient preference for imaging intensity.

Another interesting observation is that few guidelines comment on the duration of surveillance. For example, how long should a 55-year-old nonsmoker with completely resected stage I NSCLC undergo annual imaging? The American Association for Thoracic Surgery recommends an age cutoff for lung cancer screening by annual CT (79 years old); they also note that screening should not be offered, regardless of age, if comorbidities or functional status would preclude adequate treatment. ${ }^{7}$ Other guidelines make similar recommendations regarding functional status but exclude specific age cutoffs. ${ }^{6,8}$ In reality, screening regimens need to be concordant with each individual patient's goals, which no guideline or study can adequately measure.

Who performs surveillance (surgeon, oncologist, primary care provider) likely also affects practices. Some suggest that a benefit of surgeon-guided surveillance is their unique ability to review scans independently, potentially avoiding unnecessary additional interventions. ${ }^{26}$ Regardless of who performs surveillance, however, is the unmeasurable added benefit that patients may garner from regular provider interaction (smoking cessation, reassurance, etc.).

"What to do" (the modality) and "how often to do it" (the frequency) are 2 critical questions for postresection lung cancer surveillance with surprisingly poor evidence. In our practice and based on the preceding evidence, we believe that contrasted chest CT with limited abdominal evaluation is most appropriate for initial postoperative surveillance. In terms of "how often to do it," we believe that the best evidence currently supports at least annual surveillance with no benefit to more than biannual surveillance during the first several years after surgery; beyond that time, annual LDCT seems adequate. ${ }^{1,23}$

In conclusion, current guidelines for postresection surveillance tend to favor more aggressive CT-based imaging at 3- to 6-month intervals. Recent data suggest that this is likely too frequent with no impact on patient survival. Further, such frequent imaging likely only compounds patient anxiety and ever-expansive health care costs. Our group currently recommends at least annual CT surveillance following lung cancer resection.

\section{Conflict of Interest Statement}

The authors reported no conflicts of interest.

The Journal policy requires editors and reviewers to disclose conflicts of interest and to decline handling or reviewing manuscripts for which they may have a conflict 
of interest. The editors and reviewers of this article have no conflicts of interest.

\section{References}

1. McMurry TL, Stukenborg GJ, Kessler LG, Colditz GA, Wong ML, Francescatti $\mathrm{AB}$, et al. More frequent surveillance following lung cancer resection is not associated with improved survival: a nationally representative cohort study. Ann Surg. 2018;268:632-9.

2. Taylor MD, Nagji AS, Bhamidipati CM, Theodosakis N, Kozower BD, Lau CL, et al. Tumor recurrence after complete resection for non-small cell lung cancer. Ann Thorac Surg. 2012;93:1813-20; discussion 1820-1.

3. Colt HG, Murgu SD, Korst RJ, Slatore CG, Unger M, Quadrelli S. Follow-up and surveillance of the patient with lung cancer after curative-intent therapy: diagnosis and management of lung cancer, 3rd ed: American College of Chest Physicians evidence-based clinical practice guidelines. Chest. 2013;143(5 suppl): e437S-54S.

4. Wong ML, McMurry TL, Stukenborg GJ, Francescatti AB, Amato-Martz C, Schumacher JR, et al. Impact of age and comorbidity on treatment of nonsmall cell lung cancer recurrence following complete resection: a nationally representative cohort study. Lung Cancer. 2016;102:108-17.

5. McWilliams A, Tammemagi MC, Mayo JR, Roberts H, Liu G, Soghrati K, et al. Probability of cancer in pulmonary nodules detected on first screening CT. N Engl J Med. 2013;369:910-9.

6. Schneider BJ, Ismaila N, Aerts J, Chiles C, Daly ME, Detterbeck FC, et al. Lung cancer surveillance after definitive curative-intent therapy: ASCO guideline. $J$ Clin Oncol. 2020;38:753-66.

7. Jaklitsch MT, Jacobson FL, Austin JHM, Field JK, Jett JR, Keshavjee S, et al. The American Association for Thoracic Surgery guidelines for lung cancer screening using low-dose computed tomography scans for lung cancer survivors and other high-risk groups. J Thorac Cardiovasc Surg. 2012;144:33-8.

8. National Comprehensive Cancer Network. Non-Small Cell Lung Cancer, Version 6.2020. NCCN Guidelines in Oncology; 2020. Available at: https://www. nccn.org/professionals/physician_gls/pdf/nscl_blocks.pdf. Accessed September 1, 2020.

9. Postmus PE, Kerr KM, Oudkerk M, Senan S, Waller DA, Vansteenkiste J, et al. Early and locally advanced non-small-cell lung cancer (NSCLC): ESMO clinical practice guidelines for diagnosis, treatment and follow-up. Ann Oncol. 2017;28: iv1-21.

10. Moran A, Daly ME. Surveillance imaging for non-small cell lung cancer: mounting evidence that less is more. Transl Lung Cancer Res. 2019;8(suppl 4):S343-6.

11. Howlader N, Forjaz G, Mooradian MJ, Meza R, Kong CY, Cronin KA, et al. The effect of advances in lung-cancer treatment on population mortality. $N$ Engl J Med. 2020;383:640-9.

12. The National Lung Screening Trial Research Team. Reduced lung-cancer mortality with low-dose computed tomographic screening. $N$ Engl J Med. 2011;365: 395-409.
13. Hanna WC, Paul NS, Darling GE, Moshonov H, Allison F, Waddell TK, et al Minimal-dose computed tomography is superior to chest X-ray for the followup and treatment of patients with resected lung cancer. J Thorac Cardiovasc Surg. 2014;107:30-5.

14. Erb CT, Su KW, Soulos PR, Tanoue LT, Gross CP. Surveillance practice patterns after curative intent therapy for stage I non-small-cell lung cancer in the medicare population. Lung Cancer. 2016;99:200-7.

15. Westeel V, Barlesi F, Foucher P, Lafitte J-J, Domas J, Girard P, et al. Results of the phase III IFCT-0302 trial assessing minimal versus CT-scan-based follow-up for completely resected non-small cell lung cancer (NSCLC). Ann Oncol. 2017;28: v452.

16. Lou F, Sima CS, Rusch VW, Jones DR, Huang J. Differences in patterns of recurrence in early-stage versus locally advanced non-small cell lung cancer. Ann Thorac Surg. 2014;98:1755-60; discussion 1760-1.

17. Hamaji M, Ali SO, Burt BM. A meta-analysis of resected metachronous second non-small cell lung cancer. Ann Thorac Surg. 2015;99:1470-8.

18. Gauger J, Patz EF, Coleman RE, Herndon JE. Clinical stage I non-small cell lung cancer including FDG-PET imaging: sites and time to recurrence. J Thorac Oncol. 2007:2:499-505.

19. Gambazzi F, Frey LD, Bruehlmeier M, Janthur W-D, Graber SM, Heuberger J, et al. Comparing two imaging methods for follow-up of lung cancer treatment: a randomized pilot study. Ann Thorac Surg. 2019;107:430-5.

20. Reddy JP, Tang C, Shih T, Kim B, Kim C, Nguyen Q-N, et al. Influence of surveillance PET/CT on detection of early recurrence after definitive radiation in stage III non-small-cell lung cancer. Clin Lung Cancer. 2017;18:141-8.

21. Choi SH, Kim YT, Kim SK, Kang KW, Goo JM, Kang CH, et al. Positron emission tomography-computed tomography for postoperative surveillance in nonsmall cell lung cancer. Ann Thorac Surg. 2011;92:1826-32; discussion 1832.

22. Wang Y, Yeung JC, Hanna WC, Allison F, Paul NS, Waddell TK, et al. Metachronous or synchronous primary lung cancer in the era of computed tomography surveillance. J Thorac Cardiovasc Surg. 2019;157:1196-202.

23. Subramanian M, Liu J, Greenberg C, Schumacher J, Chang GJ, McMurry TL, et al. Imaging surveillance for surgically resected stage I non-small cell lung cancer: is more always better? J Thorac Cardiovasc Surg. 2019;157: 1205-17.e2.

24. Han SS, Rivera GA, Tammemägi MC, Plevritis SK, Gomez SL, Cheng I, et al. Risk stratification for second primary lung cancer. J Clin Oncol. 2017;35: 2893-9.

25. Kang J, Chowdhry AK, Milano MT. Long-term CT surveillance after primary lung cancer treatment captures events in all risk groups. Transl Lung Cancer Res. 2018;7(suppl 1):S49-53.

26. Korst RJ, Kansler AL, Port JL, Lee PC, Altorki NK. Accuracy of surveillance computed tomography in detecting recurrent or new primary lung cancer in patients with completely resected lung cancer. Ann Thorac Surg. 2006;82: 1009-15.

Key Words: non-small cell lung cancer, imaging, computed tomography, surveillance 